\title{
Formação continuada de professores: alguns conceitos, interesses, necessidades e propostas
}

\section{Continued formation of teachers: some concepts, interests, needs and proposals}

\section{Luis Eduardo Alvarado-Prada ${ }^{[a]}$, Thaís Campos Freitas ${ }^{[\mathrm{b}]}$, Cinara Aline Freitas ${ }^{[c]}$}

[a]Pós-Doutorado em Educação Universidade de São Paulo (USP), professor voluntário da Universidade Federal do Triângulo Mineiro (UFTM), Uberaba, MG - Brasil, e-mail: leaprada@hotmail.com

${ }^{[b]}$ Graduada em Pedagogia pela Universidade de Uberaba (UNIUBE), orientadora educacional escola de rede pública de ensino, Uberaba, MG - Brasil, e-mail: thaiscamposf@gmail.com ${ }^{[c]}$ Graduada em Pedagogia pela Universidade de Uberaba (UNIUBE), Uberaba, MG - Brasil, e-mail: cinaraaline@yahoo.com.br

\section{Resumo}

As concepções sobre formação continuada de professores e suas interpretações em publicações que as veiculam com relativa facilidade, mais os pensamentos dos professores, sujeitos dessa formação e quem 
as vivenciam, não estão disponibilizados para a consulta por parte dos pesquisadores de profissão, dos políticos e desses mesmos professores que, no cotidiano escolar, pouco sabem da problemática dos outros colegas e da literatura sobre a formação continuada. Por isso, a modo de síntese informativa e para fundamentar algumas de nossas análises, apresentamos dados coletados em pesquisas e no desenvolvimento de atividades de formação continuada, com os coletivos docentes de instituições escolares e outros docentes com quem os têm proporcionado ao longo de quase duas décadas. A formação de professores continua sendo um dos principais problemas da educação. Entretanto, existem problemas estruturais da sociedade e da educação que condicionam esta formação e concretamente a formação continuada da que tratamos neste texto. Estamos propondo a FCPS para ultrapassar concepções e práticas de formação continuada que não são continuadas, pouco formam, pouco valorizam e até algumas vezes desvalorizam os professores. Também estamos propondo a pesquisa coletiva como um modo de formar pesquisando e pesquisar formando. Porém com fundamentos teóricos e metodológicos de pesquisa diferenciados, que valoram os conhecimentos dos professores, objetivam a construção do coletivo para que este, compreendendo seu espaço, como um todo institucional, construa a realidade atendendo a seus interesses e necessidades.

Palavras-chave: Formação de professores. Pesquisa coletiva. Formação continuada.

\section{Abstract}

The conceptions and interpretations about continued education for teachers are in publications that convey relatively easily, but the thoughts of teachers, subjects of this experience and who experiences available for consultation by researchers, politicians and those teachers in the school daily, know just a little of the problems of other colleagues and the literature about continued education. Whence, the mode of summary information and to support some of our analysis, we present data built on research and development of continuing education activities, with a collective of teachers' schools and other teachers with whom they have provided over almost two decades. Teacher education remains one of the main problems of education. However, there are problems ideological, social, political,

Rev. Diálogo Educ., Curitiba, v. 10, n. 30, p. 367-387, maio/ago. 2010 
economic and management education that affect this formation and concretely the continued formation of which we treat in this text. We're proposing the "Continuing Formation Teachers in-Service - CFST" to overcome concepts and practices of continuing education that aren't continuous, a little form, little value and even sometimes devalue teachers. We're also proposing a collective research as a way of searching and search form forming. But with the theoretical and methodological research different, who value teachers' knowledge and aim to build the collective for it, including its space as a whole institutional construct the reality given their interests and needs.

Keywords: Teacher's formation. Collective research. Continued education.

Formar-se é um processo de toda a vida; enquanto seres humanos, temos a possibilidade de aprender e, portanto, nos humanizamos permanentemente, mediante as relações e interações que acontecem nos diversos ambientes culturais nos quais temos relações. Deste modo, aprender é mais do que receber ou obter informações e conhecê-las ou compreendê-las é tornar o aprendizado parte do ser, implicando desenvolver-se com ele. Formar-se é um processo de aprendizagem que se realiza desenvolvendo-se individual e coletivamente dentro da cultura, incorporando-a, criando e recriando-a. Como diz Assmann (1998, p. 3536), "vida é, essencialmente, aprender... e estar vivo é um sinônimo de estar agindo como aprendente."

A formação como processo de aprendizagem requer compreender as múltiplas relações dos diversos conhecimentos nas dimensões ideológicas, políticas, sociais, epistemológicas, filosóficas e/ou da área específica do conhecimento que se quer aprender. Porém, o processo de aprendizagem acontece quando, conscientemente (isto é, passado pela crítica), se incorporam ou não ao desenvolvimento individual e coletivo esses conhecimentos e as relações que os constituem.. A incorporação dessas relações depende de fatores históricos de cada pessoa, de fatores sociais cujas interações acontecem nos diversos contextos da cultura humana, das teceduras dessas relações de que cada pessoa e os coletivos fazem parte (ALVARADOPRADA et al., 2008).

Rev. Diálogo Educ., Curitiba, v. 10, n. 30, p. 367-387, maio/ago. 2010 
Entendendo que o desenvolvimento humano acontece no processo de aprendizagem e vice-versa, a formação é também um processo de desenvolvimento humano e, portanto, profissional. No caso dos docentes, estes se desenvolvem principalmente nos contextos de seu trabalho exercido na instituição escolar onde criam relações alicerçadas em estruturas complexas que as sustentam ou permitem sua alteração. Nesse sentido, espera-se que a formação continuada contribua com a manutenção, criação e alteração das relações estruturantes e estruturadoras do desenvolvimento profissional do coletivo docente na instituição escolar.

A formação, como um caminho de diversas possibilidades, permite às pessoas que o transitam desenvolver-se, construir as relações que as levam a compreender continuamente seus próprios conhecimentos e os dos outros e associar tudo isso com suas trajetórias de experiências pessoais. Assim, a formação docente é uma contínua caminhada dos profissionais da educação, em cujo caminhar atuam todas as suas dimensões individuais e coletivas de caráter histórico, biopsicossocial, político, cultural, próprias de seres integrais e autores de sua própria formação.

Os docentes em exercício constroem novos conhecimentos, ideias e práticas, pois é a partir daquilo que já possuem e sabem que continuam seu desenvolvimento. A construção da formação docente envolve toda a trajetória dos profissionais, suas concepções de vida, de sociedade, de escola, de educação, seus interesses, necessidades, habilidades e também seus medos, dificuldades e limitações.

Essa construção da formação é contínua e não fica restrita a uma instituição, à sala de aula, a um determinado curso, pois os docentes podem formar-se mediante seu próprio exercício profissional, partindo da análise de sua própria realidade e de confrontos com a universalidade de outras realidades que também têm fatos do cotidiano, situações políticas, experiências, concepções, teorias e outras situações formadoras.

Os professores, como seres intimamente ligados aos processos de aprendizagem na escola, ora alunos, ora docentes, vivenciam a realidade escolar durante a maior parte de sua vida. É nesse contexto, e a partir dele, que os profissionais da educação formam-se; em termos freirianos, leem o mundo. Nesse sentido, a análise de seu espaço escolar é necessária para compreendê-lo e fazer o confronto com outras realidades, pois ler o mundo implica ter conhecimentos que fundamentem essa leitura. O reconhecimento deste espaço como formador e seu estudo como processo de formação

Rev. Diálogo Educ., Curitiba, v. 10, n. 30, p. 367-387, maio/ago. 2010 
são atividades formativas, por sua vez, compostas de fundamentos para as leituras necessárias à formação continuada de professores.

Enunciamos anteriormente que a instituição escolar é o espaço principal onde acontecem e precisam acontecer os projetos e atividades de formação de professores. Entretanto, para isso são necessárias condições que os viabilizem como, por exemplo, a organização da gestão institucional na qual seja previsto o tempo e diversos recursos para sua realização. A escola não é a única responsável por esta formação, embora seja uma instituição educativa e/ou de formação de professores. O espaço escolar depende de relações com outras instâncias, como o próprio Estado em seus diferentes níveis, a família e todas as organizações instituídas socioculturalmente para que ela se desenvolva.

Muita responsabilidade é colocada à escola, os discursos oficiais do Governo põem a educação em lugar de destaque como fonte "salvadora" das mazelas sociais, porém, quando são necessários "cortes de gastos", a educação é sempre a primeira a sofrer as consequências. $O$ mesmo acontece com a Formação de Professores, é comum achar que esta é a salvação dos problemas de ensino, entretanto, sua trajetória histórica tem mostrado mazelas ainda a serem superadas. Problemas que vão desde o âmbito dos cursos de formação até políticas educacionais, passando também pelo posicionamento da sociedade.

Um desses posicionamentos é enunciado por Gatti (2000, p. 40): 'parece que algumas crenças do tipo 'quem sabe, sabe ensinar' ou 'o professor nasce feito' ainda predominam em nosso meio, embora a realidade esteja a toda hora contraditando essas crenças". Para a autora, a profissão docente ainda é encarada pela sociedade e pela Universidade como sendo "fácil", como algo que pode ser feito intuitivamente, dispensando uma formação de qualidade, bons materiais, boa estrutura e bons professores.

A prática pedagógica docente acontece como consequência dos saberes adquiridos na formação superior (universidade) e as experiências pessoais adquiridas durante toda a vida. Ao chegarem à universidade, os futuros ou os já docentes em exercício possuem uma bagagem muito rica e extensa, mas nem sempre valorizada e redimensionada.

Há dificuldade em associar a teoria com a prática nos cursos de formação; nestes, aprende-se teorias educativas, sociológicas, psicológicas e filosóficas e, no entanto, ignoram o cotidiano escolar. Isso é observável no impacto que os professores sofrem no início de carreira, ao encarar a realidade da escola e da sala de aula (ALVARADO-PRADA, 1997).

Rev. Diálogo Educ., Curitiba, v. 10, n. 30, p. 367-387, maio/ago. 2010 
No cotidiano escolar, ao realizarem as atividades docentes, os professores relacionam a teoria com a prática. A prática pode ser explicada e compreendida mediante a teoria e esta pode ser executada e produzida a partir da prática. A formação de professores que prioriza a parte teórica, em detrimento da prática, pode se deparar com um profissional cujos discursos sejam carregados do "dever ser do fazer" docente e da educação. Entretanto, esse fazer não condiz com as ilusões expressas no discurso do dever ser.

Nas práticas do discurso sobre formação de professores, é frequente privilegiar a transmissão de teorias, valorizando apenas alguns pensamentos ideologicamente dominantes, em detrimento da complexidade dos conhecimentos derivados das experiências individuais e coletivas construídas ao longo da vida dos docentes e que são parte deles enquanto seres profissionais. Em oposição a esse discurso, é necessário realizar processos formativos considerando a trajetória do docente, pois ela traz consigo as contradições da relação teoria-prática que, se realizadas atividades para compreendê-las, é desenvolvido um processo de formação.

\section{Conceituações da formação continuada de professores}

A formação continuada de professores sempre esteve ligada à formação de professores no sentido de se atualizar ou de manter uma educação permanente que permitisse passar para os alunos aqueles conhecimentos científicos atualizados. Mas é nos períodos pós-Primeira Guerra Mundial que a ênfase na formação continuada de professores se faz necessária por razões ideológicas, políticas e econômicas. Na década de 30, era necessário prevenir para evitar nacionalismos observados durante a guerra e também para difundir propostas pedagógicas como a Escola Nova. PosterioràSegunda Guerra, as duas grandes potências pretendiam expandir sua ideologia de diversas formas, sendo uma delas pela educação. Isso tornou necessárias as reformas educativas e, para que estas fossem implantadas na América Latina, por exemplo, era estratégico "capacitar recursos humanos" em todos os níveis (políticos, governamentais, econômicos, educativos) tendentes àimplementação das reformas. Nas décadas dos anos $60,70,80$, no auge da guerra fria, foram desenvolvidas inúmeras ações de "capacitação, reciclagem, treinamento", entre outras, que pretendiam melhorar a qualidade da educação, a alfabetização e o acesso aos produtos industriais e tecnológicos, além da formação de mão de obra qualificada.

Rev. Diálogo Educ., Curitiba, v. 10, n. 30, p. 367-387, maio/ago. 2010 
Nesse contexto, a formação de professores, a atualização ou a formação permanente foi-se constituindo num produto de consumo, inicialmente ofertado pelo Estado, o órgão que implementava as reformas ou pelo empregador dos professores. Esta formação aos poucos foi passando a ser demandada e adquirida pelos próprios professores, inclusive sendo comprada do próprio Estado.

Por volta dos anos 90, no Brasil, viveu-se um momento de inúmeras reformas, tendo a escola e a sociedade que se adequarem às novas exigências impostas pela globalização. Segundo Maués (2003), nesse período, a formação de professores teve de se adaptar às exigências e o nível superior passou a ser exigido dos docentes para trabalhar em sala de aula. Isso ocorreu porque alguns setores da sociedade defendiam, e ainda defendem, que somente na universidade os professores têm condições de aprofundar os conhecimentos e conseguir maior domínio da sua função docente. Isto levou ao que Maués (2003) nomeou como "universitarização".

Com a LDB n. 9394/96 (BRASIL, 1996), ficou determinado que, para atuar na educação básica, era necessário possuir nível superior em licenciatura ou normal superior e, para se alcançar esse objetivo, ficou estabelecido como data-limite o ano de 2007. Entretanto, estes programas na atualidade (2009) estão aquém das estatísticas e da qualidade esperadas.

Referente à formação continuada, o ideal das políticas atuais é que as várias hierarquias de instituições de ensino superior (universidades, centros universitários, faculdades integradas e institutos superiores) assumam esta formação, mas, por diversas razões, isso não tem acontecido. Entretanto, têm surgido, nos Estados e municípios, pessoas e instituições para realizá-la, atendendo mais a interesses dos governantes sem o preparo para compreender sua complexidade, e sendo, muitas vezes, administrada e ministrada por profissionais não formados e sem as condições necessárias para a complexidade de seus requerimentos.

Esse ideal pretende provocar mudanças no processo de ensinoaprendizagem, entretanto, o profissional da educação é pouco valorizado como tal. Dificilmente é considerado como aprendiz e como autor e produtor de sua própria formação.

Ter sucesso no ensino-aprendizagem mediante a formação continuada é um ideal que não será alcançado por não se considerar nessa formação as características dos professores, suas necessidades e expectativas pessoais e profissionais, seus contextos de trabalho, bem como a cultura elaborada pela instituição escolar em que eles atuam.

Rev. Diálogo Educ., Curitiba, v. 10, n. 30, p. 367-387, maio/ago. 2010 
É necessário conhecer como os professores aprendem, se formam e desenvolvem sua ação docente, uma vez que, segundo Eckert-Hoff (2002), os profissionais da educação ainda privilegiam a maneira como foram ensinados, produzindo seres incapazes de pensar por si mesmos, de analisar algo de maneira crítica e com ideias criativas, de modo a construir e reconstruir seus conhecimentos. Faz-se necessário deixar de encarar o conhecimento como algo estático e fragmentado para reconhecê-lo como um processo dinâmico, em permanente (re)construção.

A formação continuada de professores, nesse sentido, passa a ser encarada como uma ferramenta que auxilia os educadores no processo de ensino-aprendizagem de seus alunos, na busca de novos conhecimentos teórico-metodológicos para o desenvolvimento profissional e a transformação de suas práticas pedagógicas. Nesse sentido, a escola, como instituição educacional e como espaço ${ }^{1}$ de formação continuada dos professores, precisa proporcionar recursos e tempo para que os educadores possam compreender sua própria realidade institucional, analisá-la e, consequentemente, transformá-la. Assim, será desenvolvido um processo de formação que possibilite melhoria no fazer docente individual e coletivo.

A formação continuada de professores, ao longo da história da educação e de sua própria trajetória, tem desenvolvido vários conceitos e práticas dependendo de situações principalmente ideológicas, políticas, geográficas, acadêmicas e econômicas, conforme enunciado em Alvarado Prada $(1997,2003)^{2}$. Entretanto, lembramos que, durante muito tempo, ela foi e ainda é entendida como uma maneira: de suprir as lacunas existentes na formação "inicial" docente; de sanar dificuldades escolares que acontecem no cotidiano escolar; de implantar políticas, programas, projetos, campanhas, principalmente governamentais; de adquirir certificados (créditos) para ascender na carreira e/ou obter benefícios salariais; de satisfazer interesses ou necessidades de conhecimentos específicos, ou seja, cursos de curta duração que contribuem apenas para cumprir uma exigência social.

Denominações do tipo capacitação, treinamento, reciclagem e aperfeiçoamento, entre outras, correspondem a uma ideologia e uma

\footnotetext{
${ }^{1}$ Milton Santos, em seu livro Por uma Geografia Nova (2002, p. 122), considera "o espaço como um conjunto de relações realizadas através de funções e de formas que se apresentam como testemunho de uma história escrita por processos do passado e do presente"

${ }^{2}$ Nestes textos enunciamos mais de duas dezenas de termos que têm sido e continuam sendo utilizados para nomear a formação dos professores já em exercício profissional.
}

Rev. Diálogo Educ., Curitiba, v. 10, n. 30, p. 367-387, maio/ago. 2010 
concepção tecnicista da educação que apresentam preocupação com a eficácia e a eficiência na educação tal como acontece na indústria, no comércio e no mercado de capitais cujo foco principal é apenas o lucro.

Essas denominações correspondem mais a uma concepção de manipulação, de implementação de cursos curtos e rápidos, de palestras e encontros esporádicos que permitem a implantação de "pacotes" propiciadores de um maior grau de instrução ou aptidão para seguir modelos predefinidos externamente que remendam, completam algo que supostamente falta e, por sua vez, corrigem defeitos visíveis na educação. Estas concepções têm implícita, de um lado, a desconsideração dos saberes dos educadores e, de outro, o entendimento de que o faltante são os conhecimentos "científicos" que devem ser adquiridos de seus possuidores para tirar os professores de sua incapacidade. Diante disso, a formação continuada é frequentemente entendida como "capacitação" e até como "treinamento", "reciclagem" e outras conotações.

Nesse entendimento, os professores são considerados apenas consumidores de conhecimentos ou executores de tarefas e não autores dentro do processo educativo, nem gestores da sua própria aprendizagem. Diante do anterior, é necessário que nos enunciados das políticas, nas justificativas e atividades de projetos de formação continuada se objetivem e, principalmente, se criem as condições para que os professores tenham mais autonomia na construção de conhecimentos relacionados com a educação em geral e com assuntos específicos de desenvolvimento profissional docente.

De fato, nas práticas dessas concepções consumistas, os professores são desconsiderados como seres pensantes, capazes de refletir, de construir e propor novas concepções e práticas de sua própria formação continuada que enriqueça seupensare fazerpedagógico. Estaéa diferença, entre concepções que se ocupam apenas do produto; aquelas fundamentadas em processos pedagógicos ou andragógicos, de pesquisa e de formação de professores orientadas à construção de autonomia, segundo Contreras (1997); ao desenvolvimento da criatividade e experiências de ensino aprendizagem, segundo Morim (apud PETRAGLIA, 1995); à formação do pensamento e à formação política, segundo Freire (1996), Fals Borda (1985), Giroux, (1997) e outros.

Nos últimos anos, tem-se instaurado a formação dos professores que já exercem a docência com a denominação formação continuada, seguindo pressupostos da educação permanente, amplamente divulgados pela Unesco como política mundial para a educação de adultos. A Conferência dos Ministros de Educação da Organização para a Cooperaçãoe Desenvolvimento Econômico

Rev. Diálogo Educ., Curitiba, v. 10, n. 30, p. 367-387, maio/ago. 2010 
(OCDE), em 1970 lançou o slogan: "Fazendo com que a educação ao longo da vida seja uma realidade para todos" e, aos países membros, propôs empenho e realizações nessa direção durante os cinco anos seguintes.

Esse sentido de educação de adultos entendida como permanente ou durante toda a vida, acarretou em alguns setores, como os relacionados com professores, a formação continuada, entendendo-se em princípio que a formação destes profissionais não para com uma titulação e que é necessário atualizar-se para exercer a profissão.

O ato formativo, conforme Menezes (2003, p. 317), "requer, para ser coerente, uma constante reflexão sobre si mesmo sob pena de transformarse em meras práticas receitadas e petrificadas.” Deste modo, ao professor é atribuída uma reflexão sobre suas práticas. Pensamento que nas últimas décadas tem sido divulgado, entre outros autores, por Schön (1992); Nóvoa (1992); Marcelo Garcia (1992); Pérez-Gómez (1992); Zeichner (1993) e seus seguidores. Há neste pensamento um reconhecimento da existência de um conhecimento construído e utilizado pelos professores no cotidiano da prática docente e, segundo Schön (1992), as dificuldades dessa prática podem mover à reflexão sobre a ação e sobre a reflexão na ação. Por sua parte, Stenhouse (1987) desenvolve a ideia de professor pesquisador, entendendo que as tentativas dos professores para pesquisar suas práticas mobilizam a reflexão docente.

As concepções de formação de professores, fundamentadas nas ideias de reflexivo e pesquisador, têm gerado o grande perigo de responsabilizar os docentes por problemas do ensino, como a "má qualidade" da educação, dado que eles não pesquisam nem refletem sobre suas práticas nos termos dos costumes acadêmicos de universidades e centros de pesquisa.

Outro perigo é de que a racionalidade sobre a prática pode-se constituir em tarefa para um fazer técnico de reflexão e pesquisa, e também pode constituir-se em uma exploração do profissional da educação de diferentes níveis de ensino pelo acúmulo de tarefas em seus horários de trabalho e "fora" deles. Os professores, tanto os efetivos como os de contrato temporário, no cotidiano das instituições escolares, não têm, de fato, as condições reais de tempo, de orientação e de gestão requeridas para a reflexão e a pesquisa. Menos ainda nos termos que geralmente é entendida a reflexão, a pesquisa e a própria formação, pelos formadores e formuladores de políticas ao respeito.

Os termos professor-pesquisador e professor-reflexivo têm sido massificados e estão presentes numa vasta literatura. Entretanto, as

Rev. Diálogo Educ., Curitiba, v. 10, n. 30, p. 367-387, maio/ago. 2010 
atividades docentes a respeito estão longe de uma postura crítica sobre a própria formação continuada, mesmo de um bom número de formadores de professores, cujo discurso não ultrapassa a repetição de conceitos e a formulação de deveres dos professores em palestras, cursos curtos, esporádicos e fora do contexto escolar.

A produção de conhecimento, as ações de formação continuada e outras ações denominadas ou relacionadas com essa formação, em vez de aprofundar sobre os pensamentos e práticas docentes, a compreensão de suas problemáticas, a construção de propostas de transformação mais significativas institucional e socialmente, são reduzidas a um fazer técnico, distanciando o professor e sua formação do exercício crítico da/na profissão.

Diante dos diversos pensamentos sobre a formação continuada de professores e as diversas práticas ao respeito, fica esclarecido que não há modelo único. Portanto, se faz necessário conhecer esses pensamentos e práticas, analisálos criticamente e apreender isso para desenvolver novos conhecimentos, cujos produtos sejam, de fato, a transformaçãoda formaçãodos profissionais da educação.

\section{Alguns pensamentos dos professores sobre sua formação continuada}

As concepções sobre formação continuada de professores e interpretações sobre elas se encontram em publicações que as veiculam com relativa facilidade, mas os pensamentos dos professores, sujeitos dessa formação e quem as vivenciam, não estão disponibilizados para a consulta por parte dos pesquisadores de profissão, dos políticos e desses mesmos professores que, no cotidiano escolar, pouco sabem da problemática dos outros colegas e da literatura sobre a formação continuada. Porisso, a modo de síntese informativa e para fundamentar algumas de nossas análises, apresentamos dados coletados em pesquisas ${ }^{3}$ e no desenvolvimento de atividades de formação continuada,

\footnotetext{
${ }^{3} \mathrm{O}$ projeto de pesquisa do qual tomamos mais informações é o denominado "Ações de Formação Continuada de Professores desenvolvidas em municípios da região de Uberaba"; em seu desenvolvimento levantamos informações correspondentes ao período 2003 - 2008. Participaram 748 professores de 23 municípios na coleta de dados mediante questionários. Também foram realizadas oficinas de devolução de dados em 14 desses municípios, das quais participaram 577 professores e outras pessoas vinculadas às secretarias de educação, como professores de professores responsáveis pela formação continuada no município (OLIVEIRA, 2007; ALVARADO PRADA, et al., 2008).
}

Rev. Diálogo Educ., Curitiba, v. 10, n. 30, p. 367-387, maio/ago. 2010 
com coletivos docentes de instituições escolares ${ }^{4}$ e outros docentes ${ }^{5}$ com quem os têm proporcionado ao longo de quase duas décadas.

Segundo os docentes, as ações nas quais mais participam são, em sua ordem, palestras ${ }^{6}$ e oficinas, seguidas de seminários, cursos de 1 a 10 horas e congressos, ou seja, atividades pontuais, de curta duração e, portanto, sem continuidade ao logo dos meses, e muito menos dos anos escolares. Mesmo fazendo parte dos planos escolares, no cotidiano vão sendo excluídas ou adiadas para um tempo que não se tem.

As ações que mais gostaram foram as oficinas, mesmo sendo pouco ofertadas ou pouco desenvolvidas nas ações de formação. Eles justificam seu gosto, por elas apresentarem formas variadas de trabalhar, dinâmicas, debates sobre a conduta dos docentes em sala de aula enquanto prática de ensino, metodologia participativa, afirmando, assim, que na prática se observa melhor a realidade e o aprendizado é através de coisas concretas. Também gostaram das palestras e seminários, tendo em conta que nesses encontros se discutem temas considerados relevantes no exercício da profissão, porém, essas palestras, em geral, são consideradas cansativas e repetitivas, o palestrante normalmente é despreparado quanto ao contexto escolar, e faz pouca relação teoria e prática.

Os docentes enunciam que os cursos são ações frequentemente oferecidas como formação continuada, entretanto não agradaram os professores pelo fato de caracterizarem uma imposição, na maioria das vezes, pelas secretarias de educação. Alguns dizem que não são de real interesse; por serem mais exposições de temas do que conteúdos que vão ao encontro das expectativas dos docentes, pois estes, em sua maioria, querem conteúdos e metodologias para resolver situações do seu cotidiano. Buscam, nas ações de formação continuada, ajuda para resolução de problemas, a transformação de sua prática e o cotidiano da sala de aula.

\footnotetext{
${ }^{4}$ Fazemos referências ao projeto denominado estrategicamente curso "Gestão Escolar da Formação Continuada de Professores em Serviço", desenvolvido mediante um processo de pesquisa coletiva com professores do município de Uberaba, MG, com o intuito de construir um "Projeto de Formação Continuada de Professores do Sistema Municipal de Educação de Uberaba”. O projeto teve 4 fases, na primeira (ano 2005), com os professores de todas escolas municipais, foi elaborada uma proposta coletiva dos gestores e professores do município. Nos anos seguintes, 2006, 2007, 2008, foram desenvolvidos alguns projetos de FCPS com instituições como os Centros de Educação Infantil - CEMEIs (OLIVEIRA, 2006; ALVARADO-PRADA; OLIVEIRA, 2008).

${ }^{5}$ Estamos fazendo referência aos docentes com quem têm interagido em projetos e outras atividades relacionadas com formação de professores em vários países, principalmente na Colômbia e no Chile, além do Brasil.

${ }^{6}$ As palavras que se encontram em itálico, correspondem aos dizeres dos docentes que participaram de nossas pesquisas.
}

Rev. Diálogo Educ., Curitiba, v. 10, n. 30, p. 367-387, maio/ago. 2010 
Os professores consideraram relevantes ações formativas que promovam a interação e a troca de experiências, que permitam atender problemas da sala de aula, mediante debates e discussões; preferem ações cujas metodologias sejam dinâmicas, possibilitando sua participação.

Evidenciamos uma grande preferência dos professores por assuntos e questões referentes à didática de sala de aula e especificidade da área de conhecimento que cada um leciona; observamos que eles buscam na formação continuada aquilo que não tiveram em sua formação para ser professores, ou seja, procuram mediante a formação continuada preencher suas lacunas formativas para serem docentes.

Em geral, os professores justificam suas preferências pelas ações enunciadas mostrando seus interesses de crescimento profissional, por acreditarem que estas ajudam a fundamentar, analisar e aprimorar a prática pedagógica, além de acrescentar conhecimentos epropiciar o repensar dapráticapedagógica, da convivência e da postura diante do outro e da vida.

Eles enunciam que a formação continuada deveria ter periodicidade, ser realmente continuada e sugerem que ela aconteça mais vezes durante o ano; segundo os professores, é necessário ter encontros periódicos, com cargas horárias maiores $e$ mais científicas, com mais reuniões. Eles gostariam de ser atendidos em suas necessidades de formação, mediante ações de acompanhamento e formação permanentemente, realizadas e oferecidas pela instituição de trabalho, por formadores de professores experientes, mediante metodologias que favorecessem a partilha de experiências como as oficinas. Eles também gostariam que as ações contribuíssem para avanços em seus planos de carreira; gostariam que fossem cursos que realmente servissem para enriquecê-los profissionalmente.

Os professores enunciam que as ações desenvolvidas como formação continuada estão muito aquém do esperado pela maioria deles e reclamam reformulações na maneira como estas são elaboradas e desenvolvidas.

Todos esses fatores acabam por desmotivar os professores, que se veem diante de uma situação de descaso com sua condição profissional, se sentem desvalorizados de diferentes formas, uma delas no relacionado com seus conhecimentos derivados da experiência profissional docente. Entretanto, eles lutam para superar as dificuldades, para se formarem continuamente, mesmo sacrificando suas famílias, suas poucas economias, seu tempo não remunerado, sua própria saúde. São sonhadores querendo construir um mundo melhor mediante a educaşão, ou seja, mediante seu trabalho docente.

Rev. Diálogo Educ., Curitiba, v. 10, n. 30, p. 367-387, maio/ago. 2010 


\section{Pesquisa coletiva: desenvolvimento de alguns de seus fundamentos teórico-metodológicos}

A formação continuada de professores, como foi exposto na parte anterior deste texto, está sujeita a inúmeras concepções e práticas. No cotidiano da escola, as relações dos professores com os alunos, dos professores entre eles mesmos, destes com a parte administrativa ou de gestão institucional e muitas outras interações, criam um complexo contexto caracterizador do espaço de cada instituição escolar. Esse contexto constitui a unidade escolar como um todo, no sentido de totalidade de Kosik ${ }^{7}$, que se relaciona com outros elementos do universo para poder ter sua especificidade.

A escola é o espaço onde as pessoas, individual e coletivamente, interagem com o mundo do conhecimento para conhecer o mundo. A tríade alunos, conhecimentos, professores constitui rede de relações no espaço escolar, sendo socialmente, estes últimos - os profissionais da educação os responsáveis por mediar as relações de construção de conhecimentos. Esta situação cotidiana e complexa requer dos professores uma preparação que implica ter uma base de conhecimentos para aprender continuamente e, por sua vez, mediar aprendizagens por parte dos alunos.

Mediar uma forma coletiva de aprender com e dos alunos que fazem parte do espaço escolar implica o desenvolvimento contínuo de atividades de aprendizagem por parte dos mediadores dessas atividades, de tal modo que, com a própria mediação, construam as bases para seu exercício profissional. Nesse sentido, a escola é um espaço de formação continuada cujos objetos de formação e, por conseguinte, de aprendizagem, surgem das relações que acontecem no próprio cotidiano.

A formação com objetivos de profissionalização docente implica a compreensão da realidade imediata, ou seja, de seu próprio contexto escolar para, desde essa referência, poder compreender outras realidades mediatas e universais. Dificilmente os professores conseguirão fazer uma leitura de mundo $^{8}-$ em termos freirianos - se antes não fazem uma leitura de seu contexto imediato. Isto é, se os professores não têm o preparo para ler seu

\footnotetext{
${ }^{7}$ De acordo com Kosik (1989), a totalidade não é a simples soma das partes. A totalidade está composta pelas relações de suas partes. Com isso, entende-se que não há partes isoladas. Uma instituição escolar é um todo, mas como parte da sociedade mantém inúmeras relações com diversos setores desta, inclusive com outras instituições escolares.

${ }^{8}$ A alfabetização é um processo para poder ler o mundo, compreender a realidade em suas múltiplas dimesões.
}

Rev. Diálogo Educ., Curitiba, v. 10, n. 30, p. 367-387, maio/ago. 2010 
imediato, como podem ler o mundo? Como se pode exigir deles a mediação da aprendizagem de conhecimentos universalmente sistematizados e construídos por culturas distintas e diversas. tendo em conta que algumas, como a acadêmica, são fechadas em si mesma, provavelmente dificultando seu acesso, para manter ideologicamente seu poder de dominação pelo conhecimento.

A compreensão das relações que constituem a realidade do cotidiano escolar implica processos complexos de descobrimento de como essas relações estão constituídas para intencional e coletivamente constituir uma ou algumas em objeto de transformação. As atividades de construção desse objeto de transformação requerem e produzem novos conhecimentos. Ou seja, são atividades de pesquisa para compreender a realidade e, por sua vez, de formação de professores.

A pesquisa, neste sentido, objetiva a transformação da realidade e não a mera produção de conhecimentos para divulgação e, até, para a implementação de projetos em outros contextos sem antes conhecer sua realidade. Também objetiva a transformação das relações de poder, entendendo que todo ser humano tem diversos conhecimentos, os quais, porém, não tornam determinadas pessoas superiores a outras.

As atividades, tanto de pesquisa como de formação das que estamos fazendo referência, estão fundamentadas teórica e metodologicamente na Pesquisa Coletiva e na Formação Continuada de Professores em Serviço (FCPS), cuja junção pode-se entender como processos de pesquisa-formação nos quais o desenvolvimento da pesquisa é um processo formativo e viceversa, ou seja, a formação é desenvolvida pesquisando.

\section{Pesquisa coletiva e formação continuada de professores em serviço}

A pesquisa coletiva é uma forma de construir conhecimentos para compreender e transformar a realidade junto com os outros, a partir do confronto dos conhecimentos que cada ser humano tem - poderíamos denominar de restritos - com os universalmente sistematizados ${ }^{9}$. Em outro sentido, este tipo de pesquisa é um movimento de construção de coletivos

\footnotetext{
${ }^{9}$ Conhecimentos universalmente sistematizados, em outras concepções denominados conhecimentos "científicos", palavra que não utilizamos pela conotação ideológica contrária a nossos pensamentos.
}

Rev. Diálogo Educ., Curitiba, v. 10, n. 30, p. 367-387, maio/ago. 2010 
de pessoas para seu desenvolvimento humano emancipatório, mediante a compreensão de sua realidade. E, ainda, é um processo de construção da realidade ${ }^{10}$, orientando-a para alcançar objetivos coletivos.

Nesta epistemologia, as relações dos participantes na pesquisa são de sujeito-sujeito, significando que todos os membros do coletivo têm e constroem conhecimentos, portanto, é necessário valorizar esses conhecimentos, compreender e respeitar as diferenças. A expressão e compreensão da subjetividade de cada participante é um processo de construção dos objetivos, o objeto de pesquisa, a metodologia, os dados da pesquisa, contribuindo tudo isto à sua objetividade. A comunicação de todos os membros do coletivo, entre si mesmos, e de cada um com o coletivo é fundamental para compreensão e troca de conhecimentos e para a construção de consensos ${ }^{11}$. Essa comunicação implica permanente devolução dos dados, os quais estão sendo construídos, ao coletivo, para todos terem equidade na informação e possibilitar individual e coletivamente essa construção.

As concepções e práticas da metodologia da pesquisa coletiva se fundamentam principalmente no trabalho do, com e para o coletivo. Esse coletivo, fundamentados em Anton Semiónovitch Makarenko (1985) ${ }^{12}$, o entendemos como um conjunto composto por pessoas, cuja diversidade de características individuais está em contínua construção de relações que o caracterizam e lhe define um espaço de atividades cujos objetivos são mediados por elementos ideológicos, políticos, sociais e culturais comuns (ALVARADO-PRADA, 2008).

Com este entendimento, o conjunto de docentes de uma instituição escolar pode constituir-se em um coletivo que desenvolve um projeto de formação continuada de seu corpo docente em seu próprio espaço de trabalho, construindo seu próprio objeto de pesquisa-formação mediante atividades que, por um lado, permitam a compreensão de sua própria realidade e, por outro, atendam seus interesses e necessidades de formação.

Esse projeto poderá ser realmente de Formação Continuada de Professores em Serviço (FCPS) se, além de realizado no contexto do espaço

\footnotetext{
${ }^{10}$ No sentido que Berguer e Lukman (1978) explicitam em seu livro: A construção social da realidade.

${ }^{11}$ Consenso, no sentido de Habermas (2001), implica dar lugar às diferenças.

${ }^{12}$ Ele relata suas experiências pedagógicas e, a nosso entender, de pesquisa, em seu livro Poema Pedagógico, entendendo o coletivo como um organismo social vivo.
}

Rev. Diálogo Educ., Curitiba, v. 10, n. 30, p. 367-387, maio/ago. 2010 
de trabalho do coletivo docente e com base no objeto de pesquisa-formação construído por esse coletivo a partir de seus interesses e necessidades, é realizado não tempo do trabalho remunerado para os docentes.

O desenvolvimento de um projeto de FCPS tem implicações diferenciadas das atuais situações políticas, culturais, conceituais, metodológicas, jurídicas e econômicas em que se realiza a formação continuada. Uma delas é a qualidade da formação entendida como alcançar o desenvolvimento humano profissional coletivo. Mas para ilustrar essas implicações sintetizaremos, a modo de exemplo, o relacionado com a parte econômica, até porque normalmente se argumenta que a má qualidade da formação é a falta de recursos financeiros.

Um projeto municipal de FCPS poderia ser mais econômico para um município e, em consequência, obter melhores resultados dessa formação que as atuais "feras" de cursos oferecidas aos docentes e comprados, a maioria de vezes, de instituições e pessoas que se anunciam como "sem fins lucrativos". Na prática, os docentes sabem e sentem que estes cursos demandam deles gastos financeiros com deslocamento, alimentação e outros, além de muitas vezes ter de pagar parte do curso, materiais e dedicar tempo que utilizariam para descansar ou para completar sua remuneração com outro trabalho.

Cabe esclarecerque a FCPS no espaço escolar requer, para o confronto de seus conhecimentos, a colaboração de outros profissionais - formadores de professores - que orientem seus processos pedagógicos ou de pesquisa de preferência no local de trabalho onde acontecem as relações, objeto de estudo. Também os professores da escola precisam planejar coletivamente quem, como, para o que, quando ir a outros espaços (universidade, eventos acadêmicos, estágios) para fazer os confrontos de conhecimentos e as trocas necessárias ao processo de pesquisa-formação institucional.

O desenvolvimento da FCPS numa instituição ou num município supõe a instituição escolar como um espaço formador, o que demanda da gestão dessa formação, tanto no município como na escola. Isso, por sua vez, demanda de equipes de formadores de professores que contribuam ao confronto de conhecimentos. Ao final, esta formação é um direito dos professores e precisa ser mediada por profissionais que contribuam à construção coletiva do projeto institucional de FCPS.

Rev. Diálogo Educ., Curitiba, v. 10, n. 30, p. 367-387, maio/ago. 2010 


\section{Algumas considerações}

A formação de professores continua sendo um dos principais problemas da educação. Entretanto, existem problemas estruturais da sociedade e da educação que condicionam esta formação e concretamente a formação continuada da que tratamos neste texto.

Existem problemas da ordem política, cultural, econômica, conceitual e outras, porém, neste texto pretendíamos enunciar tais problemas de forma a dar lugar a propostas, não como um dever ser, mas como experiências realizadas ${ }^{13}$ que sirvam de subsídios para gerar outras, conforme os interesses e necessidades dos coletivos escolares em seus espaços.

Estamos propondo a FCPS para ultrapassar concepções e práticas de formação continuada que não são continuadas, pouco formam, pouco valorizam e até algumas vezes desvalorizam os professores. Dita proposta implica questões políticas e de cidadania que entendem a formação continuada dos profissionais da educação como um dever do Estado e um direito e dever dos professores e, a partir deste entendimento, se construa uma cultura de formação continuada de professores, em todas as instâncias escolares e municipais.

Também estamos propondo a pesquisa coletiva ${ }^{14}$ como um modo de formar pesquisando e pesquisar formando, porém, com fundamentos teóricos e metodológicos de pesquisa diferenciados que valorizem os conhecimentos dos professores e objetivem a construção do coletivo para que este, compreendendo seu espaço como um todo institucional, construa a realidade atendendo a seus interesses e necessidades. A metodologia da pesquisa coletiva implica o desenvolvimento de habilidades comunicativas - entre elas, a escrita individual e coletiva - que viabilizem a construção de dados (levantamento, sistematização e análises) e consensos necessários para a construção tanto de conhecimentos como da realidade.

\footnotetext{
${ }^{13}$ Temos desenvolvido vários projetos de Formação Continuada de Professores em Serviço durante mais de duas décadas, os quais deram subsídios para nossas concepções e práticas. Algumas delas publicadas em: ALVARADOPRADA (1997, 2001, 2006, 2008); ALVARADO-PRADA; MURCIA FLORIAN (1991); OLIVEIRA (2007); ALVARADO-PRADA; ROSA; OLIVEIRA (2003); ALVARADO-PRADA et al. (2008).

${ }^{14}$ Nos textos que temos publicado sobre a pesquisa coletiva, apresentamo-la como uma proposta a ser conhecida e colocada em desenvolvimento. Ver textos em ALVARADO-PRADA (2006, 2008).
}

Rev. Diálogo Educ., Curitiba, v. 10, n. 30, p. 367-387, maio/ago. 2010 


\section{Referências}

ALVARADO-PRADA, L. E. Formação participativa de docentes em serviço. Taubaté: Cabral Editora Universitária, 1997.

. The school as a whole in the countinuing education of theachers. In: RAYMOND, D. Noveaux espaces de développement professionel et organisationnel. Canada: Éditions du CRP, 2001. p. 85-99.

. Formação continuada de professores em serviço: formação de formadores. In: MONTEIRO, A. F.; MULLER, R. M. L. Profissionais da educação: políticas, formação e pesquisa. Cuiabá: EDUFMT, 2006. p. 116-136.

. Investigación colectiva: aproximaciones teórico- metodológicas. Estudios Pedagógicos, v. 34, n. 1, 2008. Disponível em: <http://www.scielo.cl/scielo. php?script $=$ sci_arttext\&pid $=$ S07187052008000100009\&lng $=$ pt\&nrm $=$ iso $>$. Acesso em: 22 maio 2009.

ALVARADO-PRADA, L. E.; MURCIA FLORIAN, J. Hacia un nuevo bachillerato nocturno: un informe IAP. Bogotá: Cooperativa Editorial Magistério, 1991.

ALVARADO-PRADA, L. E.; ROSA, R. M.; OLIVEIRA, V. F. A formação continuada de professores e a caracterização da comunidade escolar: os pais. In: ENCONTRO DE PESQUISAS EM EDUCAÇÃO DO CENTRO OESTE, 6., 2003, Campo Grande. Resumos... Campo Grande: ANPED, 2003.

ALVARADO-PRADA, L. E. et al. Ações municipais de formação continuada de professores na região de Uberaba. In: ENCONTRO DE PESQUISA EM EDUCAÇÃO DA ANPED DA REGIÃO CENTRO-OESTE, 9., 2008, Tagutinga. Anais... Taguatinga: ANPED, 2008. p. 1103-1116.

ASSMANN, H. Reencantar a educação: rumo à sociedade aprendente. Petrópolis: Vozes, 1998.

BERGER, P.; LUCKMANN, T. A construção social da realidade: tratado de sociologia do conhecimento. Petrópolis: Vozes, 1978.

BRASIL. Lei n. 9.394, de 20 de dezembro de 1996. Estabelece as diretrizes e bases da educação nacional. Diário Oficial [da] República Federativa do Brasil, Poder Legislativo, Brasilia, DF, 23 dez. 1996. p. 27833. Disponível em: < http:/ / www6.senado. gov.br/legislacao/ListaTextoIntegral.action?id=75723>. Acesso em: 23 mar. 2009.

Rev. Diálogo Educ., Curitiba, v. 10, n. 30, p. 367-387, maio/ago. 2010 
CONTRERAS, J. D. La autonomía del profesorado. Madrid: Morata, 1997.

ECKERT-HOFF, B. M. O dizer da prática na formação do professor. Chapecó: Argos, 2002.

FALS-BORDA, O. E1 problema de como investigar la realidad para transformar la por la praxis. 3. ed. Bogotá: Ediciones Tercer Mundo, 1985.

FREIRE, P. Pedagogia do oprimido. 17. ed. Rio de Janeiro: Paz e Terra, 1994.

. Pedagogia da autonomia: saberes necessários à pratica educativa. Rio de Janeiro: Paz e Terra, 1996.

GATTI, B. A formação de professores e carreira: problemas e movimentos de renovação. 2. ed. Campinas, SP: Autores Associados, 2000.

GIROUX, H. A. Os professores como intelectuais: rumo a uma pedagogia crítica da aprendizagem. Porto Alegre: Artes Médicas, 1997.

HABERMAS, J. Teoría de la acción comunicativa, I: racionalidad de la acción y racionalización social. Madrid: Taurus Humanidades, 2001.

KOSIK, K. Dialética do concreto. 5. ed. Rio de Janeiro: Paz e Terra, 1989.

LIBÂNEO, J. C. Reflexividade e formação de professores: outra oscilação do pensamento pedagógico brasileiro. In: PIMENTA, S. G.; GHEDIN, E. (Org.). Professor reflexivo no Brasil: gênese e crítica de um conceito. São Paulo: Cortez, 2002. p. 53-79.

MAKARENKO, A. Poema pedagógico. Brasiliense: São Paulo, 1985.

MARCELO GARCÍA, C. A formação de professores: novas perspectivas baseadas na investigação sobre o pensamento do professor. In: NÓVOA, A. (Coord.). Os professores e a sua formação. Lisboa: Publicações Dom Quixote, 1992. p. 51-76.

MAUÉS, O. C. As políticas de formação de professores: a universitarização e a prática. In: REUNIÃO ANUAL DA ANPED, 26., 2003, Poços de Caldas. Anais... Poços de Caldas: ANPED, 2003. p. 1-14.

MENEZES, C. M. A. Educação continuada de educadores: superando ambigüidades conceituais. Revista da FAEEBA - Educação e Contemporaneidade, v. 12, n. 20, p. 311-320, 2003.

Rev. Diálogo Educ., Curitiba, v. 10, n. 30, p. 367-387, maio/ago. 2010 
NÓVOA, A (Org.). Os professores e sua formação. Lisboa: Dom Quixote, 1992.

NÓVOA, A. As organizações escolares em análise. Portugal: Publicações Dom Quixote, 1999.

OLIVEIRA, V. F. Escola, espaço coletivo de Formação Continuada de Professores em serviço: limites e possibilidades. 2006. 200 f. Dissertação (Mestrado em Educação) - Universidade de Uberaba, Uberaba, 2006.

OLIVEIRA, V. F.; ALVARADO-PRADA, L. E. Construção de espaços coletivos de formação continuada de professores. In: ENCONTRO DE PESQUISA EM EDUCAÇÃO DA REGIÃO CENTRO-OESTE, 9., 2008, Taguatinga. Anais... Taguatinga: ANPED, 2008. p. 1117-1131.

PÉREZ GÓMEZ, A. O pensamento prático do professor: a formação do professor como profissional reflexivo. In: NÓVOA, A. (Ed.). Os professores e a sua formação. Lisboa: Dom Quixote, 1992. p. 13-33.

PETRAGLIA, I. C. Edgar Morin: a educação e a complexidade do ser e do saber. Petrópolis: Vozes, 1995.

SANTOS, M. Por uma geografia nova. São Paulo: EDUSP, 2002.

SCHÖN, D. A. Formar professores como profissionais reflexivos. In: NÓVOA, A. (Coord.). Os professores e a sua formação. Lisboa: Publicações Dom Quixote. Instituto de Inovação Educacional, 1992. p. 77-92.

STENHOUSE, L. La investigación como base de la enseñanza. Madrid: Ediciones Morata, 1987.

ZEICHNER, K. M. A formação reflexiva de professores: idéias e práticas. Lisboa: Educa, 1993.

Recebido: 02/04/2009

Received: 04/02/2009

Aprovado: 21/06/2009

Approved: 06/21/2009

Rev. Diálogo Educ., Curitiba, v. 10, n. 30, p. 367-387, maio/ago. 2010 